\title{
Control and Prevention of the COVID-19 Epidemic in China: A Qualitative Community Case Study
}

\author{
Yijin Wu' \\ Quan Zhang ${ }^{2,3}$ \\ Linzi $\mathrm{Li}^{4}$ \\ Meiyu $\mathrm{Li}^{5}$ \\ Ying Zuo 2 \\ 'School of Translation Studies, Qufu \\ Normal University, Rizhao, Shandong, \\ People's Republic of China; ${ }^{2}$ School of \\ International Affairs and Public \\ Administration, Ocean University of \\ China, Qingdao, Shandong, People's \\ Republic of China; ${ }^{3}$ Centre for Quality of \\ Life and Public Policy, Shandong \\ University, Qingdao, Shandong, People's \\ Republic of China; ${ }^{4}$ Rizhao Maternal and \\ Child Health Hospital, Rizhao, Shandong, \\ People's Republic of China; ${ }^{5}$ School of \\ Economics and Management, China \\ University of Petroleum (East China), \\ Qingdao, Shandong, People's Republic of \\ China
}

Background: Cross-infection among residents in communities is one of the most critical reasons for the rapid spread of the COVID-19 epidemic. The COVID-19 epidemic has been well controlled within Chinese communities, which has made important contributions to the country's fight against it.

Methods: In this study, a qualitative case study design, with mixed methods applied to data collection and analysis, was employed to explore epidemic prevention measures taken by a Chinese community, namely Mulin, during the pandemic.

Results: The Mulin community established an integrated plan for epidemic prevention, including the prevention of the invasion of COVID-19, the prevention of cross-infection within the community, gaining the residents' trust and support, and providing the residents with convenient services.

Conclusion: In the present work, the Mulin community was taken as a typical case study, and qualitative methods were employed to comprehensively summarize the practice and experience of the community's epidemic prevention. Mulin's practices could shed light on how communities in other countries, especially developing countries with large populations, can prevent the spread of COVID-19.

Keywords: COVID-19, epidemic prevention, community, China

\section{Introduction}

The novel coronavirus disease 2019 (COVID-19), which broke out in Wuhan, China, in December 2019, quickly spread to countries on all continents of the globe. Due to the fast spread of the epidemic, it was declared a public health emergency of international concern (PHEIC) by the World Health Organization (WHO) on January 30, 2020, ${ }^{1}$ and was further announced as a pandemic on March 11, 2020. ${ }^{2}$ Since then, confirmed cases of COVID-19 escalated from 148,476 on March 11, 2020, to 239,069,344 on October 11, 2021, and the death toll skyrocketed from 4635 to $4,875,438 .{ }^{3}$ As of now, this fast-spreading virus has shown no sign of abating. Because the COVID-19 pandemic has been found to be associated with highly significant levels of psychological distress and physical illness worldwide, ${ }^{4-6}$ governments of all countries and regions have adopted a series of measures to combat the virus. ${ }^{7,8}$ Due to the mature medical system and effective prevention measures present in most developed countries, including the United Kingdom, Germany, and France, the epidemic situation is generally controlled in these countries. However, many developing countries, especially large developing countries, continue to face substantial challenges in pandemic control. For example, Brazil exceeded 1 million COVID-19 cases in mid-June 2020, and has become the new epicenter of the pandemic. ${ }^{9}$ In India, confirmed cases have risen from

Correspondence: Quan Zhang

Email waltawhite@163.com 
1998 on April 1, 2020, to 33,984,479 on October 11, 2021, and the reported daily tally has exceeded 10,000 since July 2021 with no end in sight. ${ }^{10}$

Many factors have contributed to the fast spread of the pandemic, one of which is the ease with which the virus can spread in residential neighborhoods and the wider community. ${ }^{11}$ A community, as defined by WHO, is

a group of individuals that lives together in a specific geographical place, that maintains social relations among its members who recognize that they belong to such a community. ${ }^{12}$

Thus, social interactions within a community are not only central to the main function of the community, but also facilitate the spread of COVID-19, thereby exposing its residents to the onslaught of the pandemic. ${ }^{13}$ As any community tends to be the main gathering area of a population, and is characterized by high density and mobility, gatherings (including mass gatherings) and intimate contact are very common, thereby providing ample room for COVID-19 to spread within the community. ${ }^{14}$ COVID-19 is highly transmissible with various transmission routes, such as aerosol, respiratory droplets, and direct close contact, and it has a greater potential to spread in relatively closed spaces, such as neighborhoods. ${ }^{15}$ Developing nations tend to have sprawling urban centers with high-density populations, thereby increasing the risk of transmission. ${ }^{16}$ Even more vitally, COVID-19 has a relatively long incubation period, and can be spread by people who do not know they have the disease, thereby substantially increasing the risk of virus transmission within the community. ${ }^{17,18}$ All these factors have resulted in communities being the focus and most challenging areas for epidemic prevention.

When the COVID-19 outbreak in Wuhan began, one main cluster area of the epidemic was the Baibuting community. Community spread and cross-infection are the driving factors of the rapid circulation of the pandemic. ${ }^{11}$ It has also been reported that community cluster infections occurred in Japan, South Korea, Italy, and Singapore, etc. In response to this situation, WHO launched the first version of the interim guidance "Risk communication and community engagement readiness and initial response for novel coronavirus (nCoV)" in January 2020, which emphasized that multiple actors should make a joint response to the spread of the epidemic in communities, and should develop individual and group protection measures. $^{19}$ WHO further released comprehensive guidance on community prevention, namely "Responding to community spread of COVID-19: interim guidance," on March 7, 2020. ${ }^{20}$ The effectiveness of community responses to the pandemic determines, to some extent, the success of the fight against the virus.

The Chinese government has attached great importance to the community spread of COVID-19, and took a series of strict measures for epidemic prevention and control in communities nationwide. ${ }^{21,22}$ These measures have effectively controlled the community spread of the virus, resulting in a rapid decline in the rate of transmission of COVID-19. For most days between May 2020 and October 2021, China had no new cases (excluding nine days). Most of the new cases were imported, and no community cluster infections have been reported. ${ }^{23}$ Thus, the epidemic in Chinese communities has been very effectively controlled. ${ }^{24}$ In this sense, China's epidemic prevention measures that have targeted community spread have been proven effective, which could shed some light on how to conduct community epidemic control on an international scale.

It is an impossible task to summarize the epidemic prevention experiences of all communities in China. Therefore, a case study was adopted as the main research method in the present work, and data were obtained from a typical community via field research and semi-structured interviews; this method can systematically and comprehensively reproduce the measures taken by the study community to prevent viral spread. These measures are approached and analyzed from multiple aspects of epidemic prevention, including the overall planning, the organizational structure, the cooperation of multiple subjects, and any specific measures that could comprehensively reproduce the community's exposure to further threat.

\section{Methods}

\section{Methodology}

\section{Case Study Method - a Brief Introduction}

A qualitative case study approach was adopted. ${ }^{25}$ This method aims to understand the complexity of a demarcated entity by performing an in-depth and intensive analysis of the selected case. ${ }^{25}$ Given its potential for yielding the understanding of complex processes as they occur in their natural setting, qualitative case studies are being increasingly used in a wide range of health-related disciplines and fields, including medicine, nursing, and health management. ${ }^{26-28}$ The case study method is 
characterized by the use of multiple sources of evidence (eg, fieldwork, semi-structured interviews, documents). As argued by Yin, case study research is an empirical investigation that examines a contemporary phenomenon within its real-life context. ${ }^{29}$

\section{Research Design}

To comprehensively and deeply describe or explain a single case,${ }^{30}$ assure the completeness and accuracy of the findings, and overcome the limits of any single strategy or data source, researchers are encouraged to use multiple sources and strategies for data collection. ${ }^{31}$ The research strategy adopted in the present investigation, including the multiple data sources and analysis protocol, is presented in Figure 1.

\section{Quality of the Case Study Method}

The single-case study method has been criticized for its insufficiency in producing knowledge, and may lack external validity. ${ }^{32}$ However, this problem may be minor

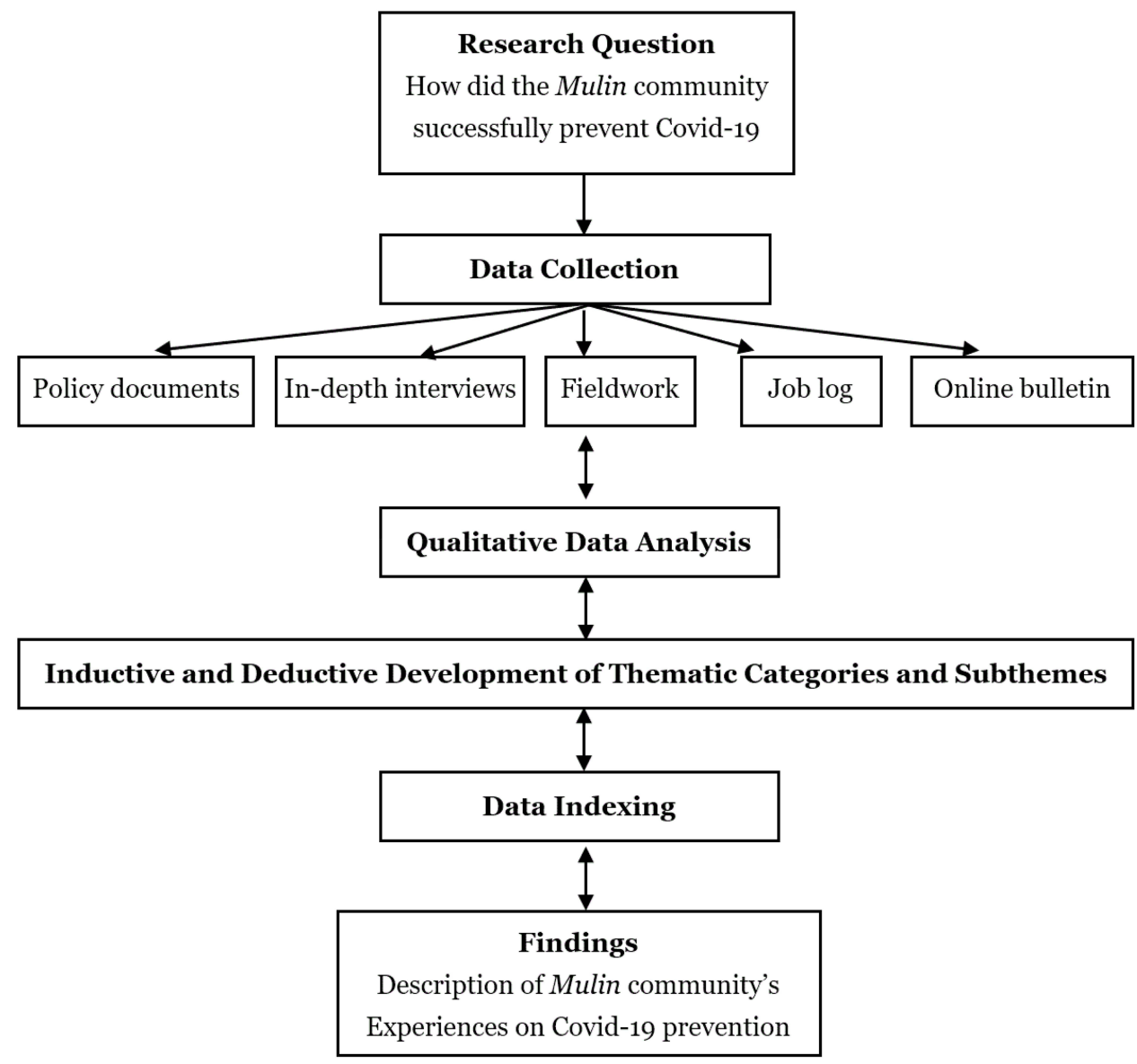

Figure I Summary of main themes and subthemes emerging from the collected data.

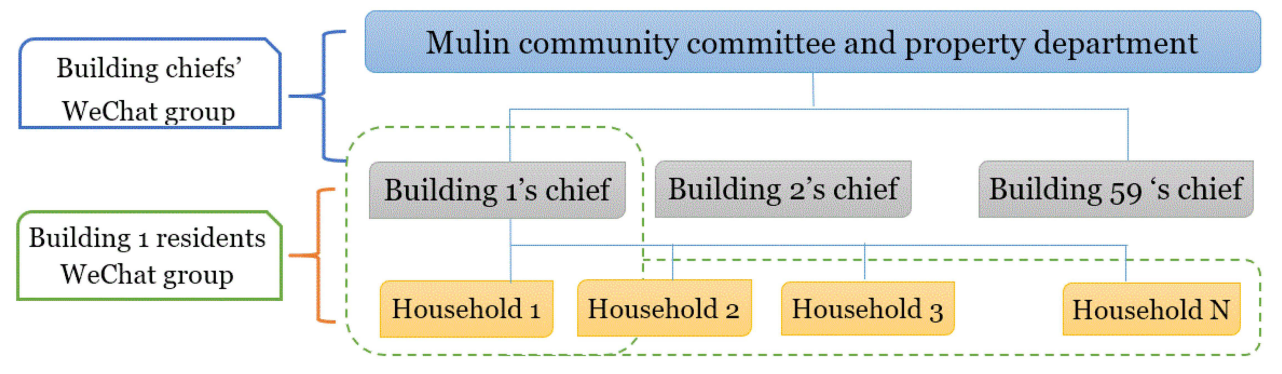

Figure 2 Hierarchical structure for information communication of Mulin community. 
insofar as a single case study has been considered applicable. $^{33}$ The credibility of the data and their interpretations have been addressed via triangulation (multiple sources), case databases, member checking procedures, and rigorous data analysis procedures. As the credibility of evidence cannot be guaranteed by a single source, five sources of data were employed in this study, ${ }^{29}$ namely policy documents, in-depth interviews, fieldwork, working files of the community committee, and the community's online bulletin board. Multiple sources of evidence gathered on the same subject can be used for cross-verification. For data that were collected from the same source/method, particularly from interviews, interviews of different participants were also used for cross-verification. For example, the five sources listed previously were adopted to investigate and analyze the issue of community closure, and the interview participants included two community committee workers, one property manager, two community guards, and five community residents; the consistency of multiple sources ensures the credibility of the study. The five sources of data form the case database of this research. ${ }^{29}$ Furthermore, the findings of this study were verified by the main participants in COVID-19 community prevention, including community workers, property managers, and residents. Strict analytical procedures were also followed for the data content analysis, which will be elucidated later.

\section{Case Selection}

In this study, the Mulin community was selected as the research case. The primary reason for this choice is that Mulin has made great achievements in community epidemic control. Mulin is a large residential community located in Qingdao, China, with approximately 12,000 residents. As an international community in a large coastal city, it houses a total of 64 foreign residents (including international students, traders, teachers, etc.) from South Korea, Japan, and Western and Middle Eastern countries; this presents substantial challenges for epidemic prevention due to the diverse cultural, lingual, and economic makeup. Moreover, Qingdao, in which the Mulin community is located, is a famous tourist city with very high population mobility; during the epidemic, 38 residents traveled to the community from Hubei (where Wuhan is located), and hundreds of residents traveled from other provinces. This increased the difficulties of epidemic prevention. However, via reasonable planning and the implementation of various actions, the Mulin community has effectively prevented the onslaught of the COVID-19 epidemic, and no confirmed or suspected cases were reported before or during the conducting of this study. Thus, Mulin is an ideal case for this research.

\section{Data Collection} Policy Documents

Policy documents produced by the government are an important data source, as they have provided guidance for the Mulin community's epidemic prevention efforts. In the process of document search and selection, a combination of methods was employed. ${ }^{34}$ Qingdao's three administrative levels of government (ie, municipal, district, and sub-district) have all been involved in the planning of community epidemic prevention. An Internet-based search of documents related to community epidemic prevention was conducted on the websites of the Qingdao municipal government, the functional departments of Qingdao city (eg, health, police, civil affairs, emergency management, etc.), and the Licang district government (where Mulin is located). Because the sub-districts of the city do not have their own websites, fieldwork was conducted to obtain documents of the J sub-district (where Mulin is located). Furthermore, a search was conducted on the Baidu search engine using the following keywords: community epidemic Qingdao, community COVID-19 Qingdao, community epidemic Licang, community COVID-19 Licang. The inclusion criteria for the official policy documents concentrated on community epidemic prevention, or whether the content involved community epidemic prevention. In total, 12 relevant policy documents were identified, as reported in Table 1.

\section{In-Depth Interviews}

In-depth interviews were conducted with the main participants of epidemic prevention in Mulin, including one community committee chairman, one community committee worker, one chief property manager, one property cleaning manager, two community guards, and five community residents. Interviews took place in a location determined by each participant, generally the community committee's office or the community's entrance, and lasted between 30 and $120 \mathrm{~min}$. All interviews were recorded and transcribed. Via a preliminary analysis of the policy documents, it was found that different actors have different responsibilities for epidemic prevention in the community. Thus, while the interview questions were concentrated on epidemic prevention, they were designed differently according to the interviewee's responsibilities. To be specific, for the interviews with the community committee 
Table I Policy Documents for Epidemic Prevention Within the Community of Qingdao City

\begin{tabular}{|c|c|c|c|}
\hline Time & Sources & Document Name & $\begin{array}{l}\text { Doc } \\
\text { Number }\end{array}$ \\
\hline January 25 & Qingdao city MHC & A letter to the citizens & Doc. I \\
\hline January 26 & Qingdao city $\mathrm{CEPCH}$ & An urgent notice to the citizens & Doc. 2 \\
\hline January 27 & Qingdao city AMR & $\begin{array}{l}\text { Notice on further improving food safety and epidemic prevention in the food circulation } \\
\text { during festivals }\end{array}$ & Doc.3 \\
\hline February I & Qingdao city $\mathrm{CEPCH}$ & Plan on the COVID-19 epidemic prevention within the community & Doc.4 \\
\hline February I & Qingdao city $\mathrm{CEPCH}$ & A letter to the citizens & Doc.5 \\
\hline February 2 & Licang district AMR & Business rules on supermarkets and restaurants during the epidemic & Doc.6 \\
\hline February 4 & Qingdao city CEPCH & Important notice epidemic prevention and control in Qingdao & Doc.7 \\
\hline February 5 & Qingdao city CEPCH & Announcement of 12 measures for epidemic prevention and control & Doc. 8 \\
\hline February 5 & Licang district $\mathrm{CEPCH}$ & Detailed rules on food safety for epidemic prevention in catering services & Doc.9 \\
\hline February 8 & Licang district $\mathrm{CEPCH}$ & Decision to implement 15 Measures for epidemic Prevention & Doc. 10 \\
\hline February 13 & Licang district AMR & Business rules on pharmacies during the epidemic & Doc.ll \\
\hline February 24 & Qingdao city CEPCH & Guidelines for Ordinary households to prevent COVID-19 & Doc. 12 \\
\hline March 13 & Qingdao city $C A B$ & Guide of assisting and safeguarding the vulnerable groups & Doc. 13 \\
\hline
\end{tabular}

chairman, the community committee worker, and the chief property manager, the questions focused on community closure, entrance management, community cleaning, information registration, home quarantine, health education, and residents' attitudes. For the interview with the property cleaning manager, the questions were concentrated on cleaning affairs during the epidemic. For the interviews with the community guards, the questions covered community closure, entrance management, registration, home quarantine, and residents' attitudes. For the interviews with community residents, the questions encompassed all issues regarding epidemic prevention to verify the preventative actions taken by the community leaders, and also to elicit the residents' attitudes toward these prevention actions. Moreover, the interviewees were encouraged to explain other community epidemic prevention actions they conduct, or to elucidate their views on epidemic prevention actions in an open manner. The demographic characteristics of the participants are reported in Table 2.

\section{Fieldwork}

Field research was originally utilized as an anthropological research method, and was then expanded to and adopted by other research disciplines such as sociology, political science, and management. ${ }^{35}$ It is currently a common method for data collection during case studies. ${ }^{36}$ This method requires researchers to go into the field and use observations and verbalizations to collect data. Because of the epidemic and the community's provisions, the present researchers were afforded only one chance, with a limited amount of time, to conduct fieldwork. Data concerning prevention practices such as community closure, health education (bulletin board), cleaning, and disinfection (work log) were collected. Although these data are unable to reveal all aspects of epidemic prevention in the community, the rich materials of the community committee's work profiles and the community's online bulletin board compensate for this deficiency.

\section{Work Log (Mulin Community Committee)}

Community committees have played a leading role in epidemic prevention. To better conduct epidemic prevention, the Mulin community committee established a detailed work log, including a summary sheet of register information, an active file of residents in quarantine, a policy database for community-based epidemic prevention, photographic evidence of community-based epidemic prevention, and a lengthy and highly detailed (containing 9636 Chinese characters) report on community epidemic prevention. The work log provides an important data source. 
Table 2 Participant's Characteristics

\begin{tabular}{|l|l|c|l|c|c|}
\hline Participants & Job Title & Gender & Age & Marital Status & Education Level \\
\hline Participant 1 & Community committee chairman & Female & 43 & Married & Post graduate \\
Participant 2 & Community committee worker & Female & 36 & Married & College graduate \\
Participant 3 & Property chief manager & Male & 52 & Married & College graduate \\
Participant 4 & Property cleaning manager & Male & 38 & Married & College graduate \\
Participant 5 & Community guard & Male & 28 & Unmarried & College graduate \\
Participant 6 & Community guard & Male & 36 & Married & High School \\
Participant 7 & Community resident & Male & 38 & Married & Post graduate \\
Participant 8 & Community resident & Male & 62 & Married & Elementary \\
Participant 9 & Community resident & Female & 48 & Married & College graduate \\
Participant 10 & Community resident & Female & 53 & Married & High School \\
Participant 1I & Community resident & Female & 59 & Middle school \\
\hline
\end{tabular}

\section{Online Bulletin Board (Mulin Community)}

Like other communities, Mulin set up an online bulletin board to inform its residents about the COVID-19 pandemic. During the COVID-19 epidemic, 116 detailed reports on community epidemic prevention actions have been delivered to the community bulletin board by Mulin community committee workers. These bulletin reports contain abundant information on epidemic prevention practices in the form of pictures, video, and text, which provide rich materials on the epidemic prevention tactics of the Mulin community.

\section{Data Analysis}

Data were organized and analyzed using inductive thematic analysis. ${ }^{37,38}$ Detailed descriptions of the experiences of the control of the COVID-19 pandemic in a Chinese community are provided by comparing the similarities and differences between coded data. ${ }^{39}$ An inductive approach was available for presenting original, first-hand, qualitative information on the Mulin community's experiences regarding the COVID-19 pandemic in China. By using multiple data sources (ie, policy documents, interviews, fieldwork, work logs, the online bulletin board), the content similarities and differences between open codes were compared to determine which codes could be grouped together.

Strict analytical procedures were followed in the data content analysis. First, the data were independently and manually coded by two researchers. Texts concerning the control of the COVID-19 pandemic were extracted and grouped into different texts. Second, a third researcher was involved in cases in which two researchers could not reach an agreement on the coding data. ${ }^{40}$ Third, codes were expanded and changed as a result of the initial coding process to ensure that the codes were "exhaustive, exclusive and enlightening." ${ }^{41}$ The independence of coding and the diversity of coders made possible the general abstraction and rich interpretation of the data. ${ }^{42}$

\section{Results}

\section{Preventing an Invasion of the Virus Within the Community}

\section{A Single Entrance and Exit}

The Qingdao government required the community to implement community closure when conditions permit, as stated in Doc. 4 ("Implement community closure to resist the virus invasion") and Doc. 10 ("Communities should maintain only 1 access channel for 24 hours if conditions permit"). During the epidemic, the Mulin community committee and property department strictly implemented this measure; they maintained only one entrance/ exit and closed all others. The one entrance/exit strategy has allowed Mulin to more efficiently prevent the invasion of COVID-19 from the outside, especially under the condition of a limited number of gate guards.

During the epidemic period, we implemented the measure of community closure, closed other entry and exit paths of the community, and retained the east gate of the community as the only path for the residents' entry and exit. There was only one garage entrance, too. Two gate guards at the east gate and one gate guard at the garage entrance keep a strict watch.

- Interview with Participant 3, chief property manager of Mulin 


\section{Exit/Entry Permitted Only for Community Residents with Health Cards}

Health cards are another method used by Qingdao city to protect the community from the virus, as indicated in Doc. 8 and Doc. 10. Health cards reflect the classification management of residents' access based on their information registration. The information registration items of the Mulin community include each resident's name, contact information, ID/passport number, body temperature for nearly 15 days, symptoms of cough and chest tightness, place of residence before returning to Qingdao, date of return to Qingdao, train/flight number, whether any stops were taken along the way, places at which stops were taken, the names of fellow passengers, etc. Residents who are in good health and have never left Qingdao are issued a valid health card. Those who have obvious symptoms of COVID-19, or have left Qingdao during the epidemic, are considered possible infected persons, and are issued an invalid health card. This task is carried out by the property guards, and all the registration information is summarized to the chairman of the community committee and creates a complete working file.

Every resident has to register his/her information before getting a community health card. If they have never left Qingdao during the outbreak, we will give them a red card after the information registration, which allows them to go in and out of the community freely. Those who have returned to Qingdao from other places after the outbreak, including Hubei and other provinces or foreign countries, will only get a yellow card, which is not a valid passport. We will require them to stay in quarantine for 14 days. After that, we will give them a red card for free access.

- Interview with Participant 3, chief property manager of Mulin

\section{Measuring the Temperature of Anyone Entering the Community}

Community residents and workers may leave the community and go into public places, so they are also at risk of infection. Therefore, the Mulin community set another condition, namely temperature checks for all persons who wish to enter the community. This was done to prevent those who may be carrying the virus from entering the community, thereby metaphorically shutting the door of the community to COVID-19.

Every person, including the residents and our property workers, for example, our managers and cleaners, must get their temperature checked before entering. If one resident's temperature exceeds $37^{\circ}$ or if they have breathing difficulties or other obvious symptoms, we will immediately report this condition to our leader (the chief property manager), who will arrange a vehicle to send him/her to the hospital for further testing.

- Interview with Participant 6, gate guard of Mulin

\section{Prohibiting Outsiders from Entering the Community} The management of the only entrance/exit is the last measure taken to resist the entry of COVID-19 into the community, as reflected in Docs. 4, 9, and 10. Residents who register their information have been deemed safe, but it is difficult to guarantee that people outside the community are not a carrier of the virus; thus, people and vehicles from outside of the community are not allowed to enter the community at any time.

During the epidemic, people and vehicles from outside of the community, including couriers and visitors, are not allowed to enter our community, because we don't know whether they are carrying the novel coronavirus. All Express packages are left with the gate sentry here for the residents to collect.

- Interview with Participant 5, gate guard of Mulin

\section{Preventing Cross-Infection in the Community Community Mobilization for Self-Protection Measures}

Considering the long incubation period of the virus, it is difficult to identify carriers of the virus, especially those who are asymptomatic. The virus may bypass the preventative measures of virus invasion by entering the community via asymptomatic infected persons, thereby posing a threat to community residents. Thus, scientific protective measures have become a necessary and effective way to prevent the cross-infection of COVID-19 in the community. The Mulin community committee has carried out health education to help the residents understand the necessity of individual and household protective measures and mobilize them to conduct these measures. Educational materials, including banners, posters, manuals, e-documents, videos, etc., are mostly provided by the government. Educational content includes information on mask-wearing, social distancing, handwashing, individual/household disinfection, good health 
habits, self-psychological adjustment, etc. These initiatives for personal protective measures were initially met with some skepticism, but were ultimately accepted by the residents and implemented successfully.

I think these measures are necessary. For example, wearing a mask can block the route of infection, and then it is a kind of protection for oneself, and also for others. You see, the number of colds caught by little children is much lower than last year, indicating that this is an effective measure.

- Interview with Participant 9, resident of Mulin

Wearing a mask does make you feel stuffy ... but it is the right thing to do, just like you wash your hands before dining. Because no one can ensure that they are not infected, it is a social morality to wear a mask. If we saw a resident not wearing a mask, we would question his behavior: why don't you abide by the public rules?

_- Interview with Participant 11, resident of Mulin

\section{Home Quarantine for I4 Days}

Home quarantine is another measure for the prevention of cross-infection of COVID-19, which, as stated previously, has a long incubation period. Because China does not have sufficient medical resources to screen asymptomatic infected persons, the relatively inefficient but useful measure of home quarantine has been implemented. As conveyed in Docs. 4, 5, 7, 8, and 10, the Qingdao government requires two groups of citizens to implement home quarantine, namely those who have traveled in the most affected provinces, such as Hubei, Hunan, Henan, and Zhejiang, during the epidemic, and close contacts of confirmed or suspected infected persons. The Mulin community committee and property management staff developed a detailed work plan for home quarantine, as described below. A special file is set up for each of the quarantined residents, which records his/her personal information, physical condition, and psychological status during the 14-day quarantine. The work plan for home quarantine is as follows:

1) The property's cleaning personnel disinfect the doorway of the quarantined resident three times per day; 2) the property's gate guard greets quarantined residents and asks about their needs via walkie-talkie, and makes sure they stay at home; 3) property staff collect the body temperature and physical condition of quarantined residents and their families through a WeChat group twice per day; 4) considering that quarantined residents cannot go shopping, the property staff purchases goods for the quarantined residents according to their requests, and leaves the goods at their doorway for them to collect with zero contact.

— Work file for one quarantined resident of Mulin, permitted to access

\section{Space Disinfection and Waste Management}

The disinfection of community spaces aims to kill the virus and prevent virus cross-infection within the community. In Docs. 4 and 10, communities are suggested to implement the disinfection of shared spaces, including elevators, staircases, underground garages, and building halls. However, the Mulin community has done even more than this. In addition to the suggested measures, outdoor spaces, corridors, sewers, and waste receptacles are all disinfected twice per day, and elevator buttons and door handles of each household are all disinfected once per day. In addition, as quarantined residents are potential carriers of the virus, property cleaning personnel disinfect the doorways of quarantined residents three times per day. Their household waste is also disinfected thoroughly, and waste management is another important measure.

Our residents' garbage is disinfected before disposal. We also set up a special trash can for discarded masks, which are disinfected and removed separately. Because some criminals may disinfect the used masks and sell them again, which poses a great threat to society, we put a special trash can at the gate, which is watched by the guard. No one can open the trash can without permission. We want to protect our residents and also the whole society.

- Interview with Participant 4, property cleaning manager of Mulin

\section{Cancellations of Public Gatherings}

Mulin is a community with high neighborhood capital, and there are various neighborhood clubs, including a table tennis club, yoga club, parent-child club, Chinese painting club, square dance team, etc. Although these activities bring happiness to the residents, public gatherings still present risks of cross-infection. During the epidemic, all the clubs in Mulin halted their activities at the instruction of the community committee; these measures, although restrictive for the neighborhood, were favored by most of the community residents. 
The cancelation of aggregation, I think, is to avoid crossinfection; cross-infection can lead to mass infection, right? It's an outbreak within a group, and even in our community. Nobody wants to see those terrible things.

\section{_ Interview with Participant 7, resident of Mulin}

It's really a pity not to see good friends in the community, but later we all realized that long-term health is more important than short-term happiness. As the saying goes, to lose is to gain. Since the epidemic is so contagious, we should all follow the rules of the community and make some sacrifices.

-Interview with Participant 10, resident of Mulin

\section{Maintaining Communication with the Residents \\ Communication Channels}

The communication of information to community residents is the propellant for the smooth implementation of community epidemic prevention. During the epidemic, the Mulin community used multiple channels to communicate with its residents, including non-digital means (eg, banners, posters, manuals, sound trucks) and via online channels. Regarding the non-digital means, the Mulin community has displayed banners and posters about epidemic prevention on all the bulletin boards, the doors of each building, and all the elevators, which aimed to make residents more aware of the community's prevention plan. Regarding the online methods, the community committee has posted information on the community's online bulletin board, namely Mulin's official WeChat account, and has sent information to the residents through a hierarchical structure with the help of WeChat groups (Figure 2). In this way, information can be quickly transmitted to each resident.

Health education materials and epidemic prevention measures related to the residents are distributed to the building chiefs (all volunteers) The WeChat group includes all 59 building chiefs in our community. The building chiefs then send these materials to the WeChat group of their own building's residents. For example, Xinjiang has recently been the epicenter of the epidemic. We will inform those who have recently returned from Xinjiang to register in the community as soon as possible, and then to go to Hongxing Hotel for a nucleic acid test. In this way, the community's epidemic prevention policies can be quickly transmitted to every resident. There are so many people in
China; this mechanism can help us to communicate with the residents in a better way, and it indeed plays an important role in the epidemic prevention of our community.

- Interview with Participant 1, Chairman of the Mulin community committee

\section{Communication Contents}

Government policy and community prevention measures are important communication contents of the Mulin community. The advocacy of government policy and community prevention measures aims to help the residents understand the necessity of prevention measures, such as community closure, information registration, and home quarantine, and to promote cooperation with the staff who conduct these measures. Docs. 1, 2, 5, 8, 10, and 12 from the various levels of government have been posted on the gate and bulletin boards of the Mulin community. Furthermore, a set of 12 colored posters produced by the Licang government are also posted on the community bulletin board, and explain in detail the necessity and benefits of community epidemic prevention measures. Moreover, temporary measures formulated by the community committee are pushed to community residents through the WeChat group.

It is very necessary to publicize the policy, because we not only want the residents to know what our community's epidemic prevention measures are, but we also try our best to let them understand why we adopt such measures; in this way, we can gain the understanding and support of the residents. Although the majority of residents accept our policies, there are still very few who do not, so our community workers have to explain to them on a call. One resident couldn't understand why his relative who came back from Hubei couldn't live with him in our community, so we needed to communicate with him repeatedly.

- Interview with Participant 1, Chairman of the Mulin community committee

The daily work and phase progress of epidemic prevention are the other two communication strategies adopted in the Mulin community. At the beginning of the epidemic, the residents had only a vague understanding of the risk of COVID-19, resulting in psychological distress and anxiety. The Mulin community explored various communication strategies to appease the mood of the residents. For example, the community committee sent daily pictures of the prevention measures taken, such as community 
disinfection, community closure, and entrance management, to the community residents through the WeChat group, thereby helping the residents to realize that their community is safe and healthy. Moreover, various types of epidemic prevention progress are written into reports and pushed to the community's online bulletin board, which also enhances the residents' confidence in defeating the epidemic. Some report titles are provided below.

January 2. Epidemic prevention: Mulin community is taking action.

February 15 . We guard the community for you, waiting for the night to pass.

February 20. "Let's join epidemic prevention"; the actions of the post-90s generation.

March 5. Let us know about epidemic prevention volunteers.

April 7. Community committee manager Sun has done a lot to defeat the epidemic.

May 1. Young volunteer propagandizes garbage classification during the epidemic.

August 10. Our community's volunteer group has been designated as the best volunteer team in Qingdao city.

Online bulletin board (official WeChat account) of the Mulin community

\section{Providing Convenient Services for the Residents Shopping Service}

While any community's epidemic prevention measures can protect the residents, they also bring inconvenience to their daily lives. The Mulin community explored different types of convenience services, one of which is a shopping service. The Mulin community committee teamed up with local supermarkets to provide a "Buy for Me" service for the residents. The residents send their shopping lists to the WeChat group, and the property staff collect the lists and send them to the supermarkets, which then deliver the goods directly to the residents' buildings. This not only provides convenience for residents, but also reduces crossinfection during the shopping process. Shopping services also provide daily necessities to quarantined residents, which helps guarantee compliance with the quarantine measures.

During COVID-19, the Mulin community's social organizations along with its supermarkets have provided fresh vegetables, meat, and fruit for those residents who don't want to go outside ... The staff of the supermarket put the packages of meat, fruit, and vegetables that the residents order in the WeChat group into 10 fixed places, and the residents receive them in batches. This not only avoids cross-infection during shopping, but also solves the problem of inconvenient shopping during the epidemic.

—CCommunity residents' food baskets are always full," Online bulletin board

(official WeChat account) of the Mulin community, February 13

\section{Online Healthcare}

The outbreak of COVID-19 has resulted in huge pressure on both big hospitals and small clinics. Many patients with chronic and minor diseases have refused to go to the hospital for fear of cross-infection in the process of seeing a doctor. Thus, Mulin's Health Service Centre and a private clinic, along with several volunteers, have provided online medical services for Mulin residents during the epidemic. Furthermore, they also provide services for purchasing and mailing medicine. This service has played a positive role in ensuring the health of patients with preexisting chronic diseases and conditions during the epidemic.

The Mulin community alongside Yinuo Clinic launched free online medical services for community residents. Yinuo Clinic's 18 doctors provided their contact information, and volunteers from the "elderly doctor's service team" will also participate in the service. In addition, we will also provide door-to-door services for residents with limited mobility.

— "Online medicine is online to fight the epidemic," Online bulletin board

(official WeChat account) of the Mulin community, February 3

\section{Online Leisure}

As neighborhood clubs stopped their activities, residents faced the dilemmas of loneliness and boredom. Mulin's community clubs tried to explore providing their services online, thereby continuing to offer leisure activities for residents. The community's Beijing opera club, Red Leaf recitation club, and yoga club posted their work on the community bulletin board. In addition, the community committee along with the Licang district cultural center launched online micro-courses on the bulletin board for 
residents, including courses on painting, calligraphy, and drama. Some of the online leisure items are listed as follows.

January 2. Epidemic prevention: Mulin community is taking action.

March 1. Works form Red Leaf recitation: The spirit of epidemic prevention.

March 7. Epidemic prevention, Beijing Opera - Spring filled the garden after the epidemic.

April 1. Micro-class online: Dynamic yoga Vol. 28.

April 23. Micro-class online: Summer baking lesson Vol. 6.

May 12. Micro-class online: Piano and vocal music.

June 19. "Happy Go" is online: Free lesson for a children's picture book.

_ Online bulletin board (official WeChat account) of the Mulin community

\section{Discussion \\ Experiences of Mulin Community's Epidemic Prevention}

Through a series of measures, the Mulin community has successfully brought the COVID-19 epidemic under control. The experiences of Mulin are summarized as follows.

First, Mulin's community epidemic prevention plan consists of the following two aspects. On one hand, community closure measures, such as a single entrance/exit, the necessity of a health card and temperature checks for community access, and banning the entry of outsiders into the community, are used to prevent the invasion of the virus from outside of the community. On the other hand, mobilization for self-protection measures, home quarantine, the disinfection of shared spaces, and the cancellation of mass gatherings are used to prevent cross-infection within the community. Mulin's measures aim to cut off all the transmission paths of the virus, which should be the common strategy for the fight of all communities against the pandemic worldwide. ${ }^{43}$ In developed countries, techniques such as rapid antigen/antibody detection, ${ }^{44}$ nasopharyngeal swabs, ${ }^{45}$ and drive-through screening ${ }^{46}$ are used for community screening to identify confirmed and suspected cases in residential communities. Welldeveloped grassroots medical systems are further used to track and quarantine these confirmed/suspected infected persons, and to provide them with medical treatment or relief. $^{47,48}$ The Mulin community, however, lacks the capacity of virus testing for the residents, and has no competent doctors to provide infected persons with medical relief; thus, it cannot afford to be affected by a cluster infection. Therefore, the Mulin community must use simple methods to prevent the virus, namely community closure to resist the virus, rough methods (information registration) to screen for possible infections, and the quarantining of numerous people with a higher risk of infection (residents returning from an outbreak area, close contacts of confirmed/suspected infected persons).

Second, a good mobilization strategy and convenient services are used to gain residents' support and reduce the negative effects of the measures on the residents, thereby promoting the smooth implementation of prevention measures. In line with previous studies, it was found that social mobilization and communication can eliminate the anxiety and distrust of the public, and can facilitate their cooperation. $^{49,50}$ Just as participant 1, Chairman of the Mulin community committee, says,

We seldom encounter trouble-makers at work; most of the residents cooperate with our work. They know that we are doing the right thing for everyone's safety, so they understand us.

Convenient services for the residents, such as shopping services, online medical care, and online leisure activities, have also reduced the negative effects of prevention measures and made them more acceptable to the residents. Just as one Mulin resident stated,

Community workers did a lot of work for us during the epidemic, and we are really touched. I heard that a volunteer group cooked lunch for them every day, because they were too busy to go home for lunch.

Thus, providing multiple services to the residents during the epidemic has been an innovative approach adopted by the Mulin community.

Third, multiple bodies are involved in the epidemic prevention of the Mulin community, including the community committee, property management staff, health service centers, private clinics, supermarkets, and volunteers, which has effectively addressed the shortage of human resources for epidemic prevention. This confirms the initiative of $\mathrm{WHO}^{51}$ and the advocacy of many health experts. ${ }^{52,53}$ Various subjects play important roles in epidemic prevention around the world, including local leaders, community and faith-based organizations, community groups, ${ }^{54}$ medical staff (eg, community 
doctors,${ }^{55}$ healthcare workers, ${ }^{56}$ medical specialists ${ }^{57}$ ), health facilities (eg, community hospitals, ${ }^{58}$ health centers, ${ }^{59}$ community pharmacies ${ }^{60}$ ), residents, ${ }^{61}$ and volunteers. ${ }^{62}$ Compared with many communities in developed countries, China does suffer from a lack of health personnel and medical facilities at the community level, and the development of non-governmental organizations (NGOs) and voluntary organizations is also lagging. The same is true of the Mulin community; medical staff, healthcare facilities, NGOs, and volunteers have not played a significant role in epidemic prevention in Mulin. Under such adverse conditions, the Mulin community committee has mobilized all available resources and entities under the existing conditions for epidemic prevention.

\section{Reflections on Mulin's Epidemic Prevention Methods}

Due to a lack of a sufficient number of doctors, healthcare workers, and mature medical facilities, the Mulin community has been unable to provide virus testing for residents, let alone medical relief and treatment for any infected residents. Under these conditions, the Mulin community took action to prevent the invasion and spread of the virus via the behavioral intervention of community residents, including community closure, traffic restrictions, gathering cancellations, and home quarantine, all of which are deemed as effective prevention measures. ${ }^{63,64}$ However, these effective prevention measures are also characterized by negative effects.

First, these measures may disturb the residents' lives. Community closure may bring inconvenience to the residents, eg, it may require some residents to walk a longer way to get in and out of the community. All residents must wear masks, and may suffer from respiratory discomfort. The cancellation of public gatherings also deprives residents of the pleasure of participating in community activities and interactions. Moreover, some quarantined residents must temporarily cease going to their job, and therefore incur economic losses. This has happened not only in the Mulin community, but also in many communities throughout China. ${ }^{65}$

Second, substantial prevention tasks have placed huge burdens on the personnel involved in epidemic prevention, including the community committee workers and property staff. According to Chairman Xing of the community committee, all the committee workers have been working on epidemic prevention since the second day of the lunar New Year, and no one has received a weekend off since then. The burden is not only physical, but also mental. Just as Participant 4, a property cleaning manager, stated,

At the beginning, our cleaners refused to work; they were afraid of getting infected with the virus ... As a manager, I was also under great pressure; I am afraid that our community will encounter a cluster of infections, or even a single case. If one case happens, the whole community will be at risk.

\section{The Extent to Which Mulin's Measures Can Be Replicated Elsewhere}

The Mulin community established an integrated plan for epidemic prevention, including preventing the invasion of the virus from outside of the community, preventing crossinfection within the community, gaining the residents' trust and support via information communication, and ensuring the smooth implementation of prevention measures using convenient services. All these measures aim to cut off all the transmission paths of the virus. Most of the specific epidemic prevention measures taken by Mulin are technical and practical, and are absent of political orientation; thus, they could be applied to other countries. For instance, personal protective measures and space disinfection are used to prevent cross-infection within the community; community mobilization, policy advocacy, and prevention progress updates are used to gain the residents' trust and cooperation; convenient services such as shopping services, online medical care, and online leisure activities are used to ensure the smooth implementation of the prevention measures. Moreover, the Mulin community's working mechanism for epidemic prevention, including a bureaucratic mechanism for information communication and a flat mechanism for work coordination, have improved the efficiency of communication with residents and work coordination among multiple bodies, which is of great value for epidemic prevention within the community.

As reported in the Community Mitigation Framework published by the US Centers for Disease Control and Prevention (CDC), every community is unique, and appropriate mitigation strategies should be taken on the basis of the characteristics of each community, such as its population, healthcare system, public health capacity, and local capacity to implement strategies. ${ }^{17}$ Several prevention measures may only be applicable to the political and 
cultural contexts of specific countries. For example, the Mulin community requires all residents to register their information relevant to the epidemic, which covers their health status, travel routes, close contacts, etc.; while this measure would be accepted by East Asian countries such as China, Japan, and Singapore, ${ }^{66,67}$ it may be considered as an infringement of privacy in Western countries. A new Pew Research poll titled "How Americans see digital privacy issues amid the COVID-19 outbreak" illustrates varying concerns a US adult may have regarding privacy. ${ }^{68}$ In addition, the Mulin community requires its residents to comply with community closure measures and conduct home quarantine, which may be considered as a restriction of personal freedom in Western countries. For example, there have been demonstrations against home quarantine and home isolation in France, the United Kingdom, Germany, and the US. Therefore, personal information investigation and home quarantine should be treated with caution when applying these measures to other countries and regions.

On the technical level, the Mulin community's epidemic prevention measures are particularly well suited to communities with high population densities and lessdeveloped primary medical care facilities (which are often found in developing countries). Although the prevention plan and measures of the Mulin community have involved a large amount of work and may have introduced some disturbance to the residents, they are very effective, easy to operate, and require few medical personnel. Mulin successfully prevented the epidemic with limited medical personnel and few resources, and can therefore act as a good example for developing countries with large populations.

Nevertheless, it should be noted that Mulin's measures are incomplete, and should be combined with measures adopted by other countries to better combat the epidemic. For example, Vietnam utilized multiple transmission routes to cover COVID-19 health information needed by the community leaders, healthcare workers, and general public, which could equip them with adequate knowledge related to the epidemic to achieve an effective response. ${ }^{69}$ This measure could be combined with Mulin's measure of maintaining communication with its residents. Better access to COVID-19 health information could help community workers implement better risk communication with community residents. To improve the operational readiness capacities of the grassroots healthcare system in the response to the COVID-19 epidemic, a collaborative mechanism between healthcare workers, medical students, community workers, social organizations, and citizen-based groups was founded at the grassroots levels around Vietnam, which could make full use of all resources available for epidemic prevention. ${ }^{70,71}$ The Mulin community could also enrich and expand its existing measures by establishing a broader collaborative mechanism. The role of village healthcare workers in epidemic prevention in Vietnam also demonstrated that community opinion leaders with professional skills should play a more important role in epidemic prevention. ${ }^{72}$ Moreover, because COVID-19 vaccines have been developed and are being rolled out and administered across all countries and regions around the world, the Mulin community should combine its existing epidemic prevention actions with vaccination promotion, and should take multiple measures to increase residents' willingness to receive the COVID-19 vaccine, ${ }^{73-76}$ this could be a topic for future research.

\section{Conclusion}

The coronavirus disease 2019 (COVID-19) outbreak in Wuhan, China, in December 2019, quickly spread to countries on all continents. Community spread and crossinfection are the driving factors of the rapid spread of the pandemic. Community epidemic prevention is not only an initiative from WHO, but is also a great challenge for communities worldwide. The prevention measures taken by China's communities have effectively controlled the spread of the epidemic, which has made important contributions to the country's fight against it. In this research, the Mulin community in China was considered as a typical case, and case study methods were employed to comprehensively summarize the practice and experience of the community's epidemic prevention. The findings of this research could shed some light on how communities in other countries, especially developing countries with large populations, can prevent the spread of COVID-19.

\section{Abbreviations}

COVID-19, corona virus disease 2019; PHEIC, public health emergency of international concern; WHO, World Health Organization; nCoV, novel coronavirus; MHC, municipal health commission; CEPCH, COVID-19 epidemic prevention and control headquarter; AMR, admiration for market regulation; CAB, Civil Affairs Bureau; NGOs, non-governmental organizations; CDC, centers for disease control and prevention. 


\section{Data Sharing Statement}

The original data will not be shared to protect participant confidentiality; however further information that does not compromise data confidentiality can be obtained from the corresponding author on reasonable request.

\section{Ethical Approval}

This study complies with the Declaration of Helsinki. Ethical approval was obtained from the Ocean University School of International Affairs and Public Administration Ethics Committee (OUC-SIAPA 202005). Written informed consent was obtained from all study participants. We have anonymised all quotes and names given in this manuscript. All participants have provided written consent to publish anonymised quotes. Confidentiality was censured by ensuring data was stored securely at all times.

\section{Acknowledgments}

The authors would like to extend their appreciation to those study participants who volunteered to participate in this research.

\section{Funding}

This research was supported by the Natural Science Foundation of Shandong Province, China [Grant ID: ZR2021QG015]. The funding body did not influence this paper in any way prior to circulation.

\section{Disclosure}

The authors declare no conflicts of interest for this work.

\section{References}

1. World Health Organization. Novel coronavirus (2019-nCoV) situation report 11; 2020. Available from: https://www.who.int/docs/defaultsource/coronaviruse/situation-reports/20200131-sitrep-11-ncov.pdf? sfvrsn=de7c0f7_4. Accessed January 31, 2020.

2. World Health Organization. WHO announces COVID-19 outbreak a pandemic. Available from: https://www.euro.who.int/en/health-topics /health-emergencies/coronavirus-covid-19/news/news/2020/3/whoannounces-covid-19-outbreak-A-pandemic. Accessed May 11, 2020.

3. Worldometers. Coronavirus worldwide graphs. Available from: https:// www.worldometers.info/coronavirus/worldwide-graphs/. Accessed October 11, 2021.

4. Xiong JQ, Lipsitz Y, Nasri F, et al. Impact of COVID-19 pandemic on mental health in the general population: a systematic review. $J$ Affect Disord. 2020;277:55-64. doi:10.1016/J.JAD.2020.08.001

5. Wang CY, Chudzicka-Czupała A, Tee ML, et al. A chain mediation model on COVID-19 symptoms and mental health outcomes in Americans, Asians and Europeans. Sci Rep. 2021;11(1):1-12. doi:10.1038/s41598-021-85943-7
6. Wang CY, Tee M, Roy AE, et al. The impact of COVID-19 pandemic on physical and mental health of Asians: a study of seven middle-income countries in Asia. PLoS One. 2021;16(2):e0246824. doi:10.1371/journal.pone.0246824

7. Lee Y, Lui LMW, Chen LD, et al. Government response moderates the mental health impact of COVID-19: a systematic review and meta-analysis of depression outcomes across countries. J Affect Disord. 2021;290:364-377. doi:10.1016/j.jad.2021.04.050

8. Hale T, Angrist N, Goldszmidt R, et al. A global panel database of pandemic policies. Nat Hum Behav. 2021;5(4):529-538. doi:10.1038/ s41562-021-01079-8

9. Pedro F, Gabriel S. Brazil passes 1 million coronavirus cases with no end in sight. Available from: https://www.msn.com/en-us/news/ world/brazil-to-exceed-1-million-covid-19-cases-as-virus-rages/arBB15IZhW. Accessed June 20, 2020.

10. Worldometers. Worldometer's COVID-19 data: India. Available from: https://www.worldometers.info/coronavirus/country/India/. Accessed October 11, 2021.

11. James S, John A. COVID-19 Infection diagnosis: potential impact of isothermal amplification technology to reduce community transmission of SARS-CoV-2. Diagnostics. 2020;10(6):399. doi:10.3390/ DIAGNOSTICS1006039

12. Aabel G, Fernando G, Esther W. Community and sense of community: the case of an urban barrio in Caracas. J Community Psychol. 1999;27(6):727-740. 27:6<727::AID-JCOP7>3.0.CO;2-Y

13. Millar J. Modelling Community spread of Covid-19 without complex mathematics. Tasman Med J. 2020;2(2):35-40.

14. Lasry A, Kidder D, Hast M, Poovey J. Timing of community mitigation and changes in reported COVID-19 and community mobility - Four U.S. Metropolitan Areas, February 26-April 1, 2020. Morb Mortal Wkly Rep. 2020;69(15):451-457. doi:10.15585/MMWR.MM6915E2

15. Sahu KK, Kumar R. Preventive and treatment strategies of COVID-19: from community to clinical trials. J Family Med Prim Care. 2020;9(5):2149-2157. doi:10.4103/JFMPC.JFMPC_728_20

16. Chetambath R, Jesin KC. COVID 19: how to tackle community spread? Indian Pract. 2020;73(3):9.

17. Centers for Disease Control and Prevention (United States). Community mitigation framework. Available from: https://www.cdc. gov/coronavirus/2019-ncov/community/community-mitigation.html. Accessed May 19, 2020.

18. Anelli F, Leoni G, Monaco R. Nume Italian doctors call for protecting healthcare workers and boosting community surveillance during Covid-19 outbreak. BMJ. 2020;368:m1254. doi:10.1136/BMJ.M1254

19. World Health Organization. Risk communication and community engagement readiness and initial response for novel coronaviruses (nCoV): interim guidance. Available from: https://apps.who.int/iris/ bitstream/handle/10665/330377/WHO-2019-nCoV-RCCE-v2020. 1-eng.pdf?sequence=1\&isAllowed=y. Accessed January 07, 2020.

20. World Health Organization. Responding to community spread of COVID-19: interim Guidance. Available from: https://www.who.int/ publications/i/item/responding-to-community-spread-of-covid-19. Accessed March 07, 2020.

21. Tan W, Hao F, McIntyre RS, et al. Is returning to work during the COVID-19 pandemic stressful? A study on immediate mental health status and psychoneuroimmunity prevention measures of Chinese workforce. Brain Behav Immun. 2020;87:84-92. doi:10.1136/BMJ. M1254

22. Zhang S, Wang Z, Chang R, et al. COVID-19 containment: china provides important lessons for global response. Front Med. 2020;14 (2):215-219. doi:10.1007/s11684-020-0766-9

23. Worldometers. Total coronavirus cases in China. Available from: https://www.worldometers.info/coronavirus/country/china/. Accessed July 23, 2020. 
24. Lu L. Community epidemic prevention in China: administrative system, multiple actions and future prospect. Soc welf. 2020;9 (3):14-19.

25. Denzin NK, Lincoln YS, eds. The Landscape of Qualitative Research. Thousand Oaks: Sage; 2008.

26. David AA, Stuart A, Sarah N, et al. Social and health system complexities impacting on decision-making for utilization of oncology and palliative care in an African context: a qualitative study. J Palliat Care. 2020;35(3):185-191. doi:10.1177/0825859719892084

27. Radka B, Radka K, Lubica J. The unmet needs of patients with progressive neurological diseases in the Czech Republic: a Qualitative Study. J Palliat Care. 2019;34(1):38-46. doi:10.1177/ 0825859718800489

28. Taylor EP, Doolittle B. Caregiver decision-making for terminally ill children: a Qualitative Study. J Palliat Care. 2020;35(3):161-166. doi:10.1177/0825859719885947

29. Yin R. Case Study Research: Design and Methods. 2nd ed. Thousand Oaks: Sage; 2014.

30. Guetterman TC, Fetters MD. Two methodological approaches to the integration of mixed methods and case study designs: a systematic review. Am Behav Sci. 2018;62(7):900-918. doi:10.1177/ 0002764218772641

31. Denzin NK, Lincoln YS. Collecting and Interpreting Qualitative Materials. Thousand Oaks: Sage; 2012.

32. Blichfeldt BS. Innovation and entrepreneurship in tourism: the case of a Danish caravan site. PASOS Revista de Turismo y Patrimonio Cultural. 2009;7(3):415-431. doi:10.25145/J.PASOS.2009.07.030

33. Teddlie C, Yu F. Mixed methods sampling: a typology with examples. J Mix Methods Res. 2007;1(1):77-100. doi:10.1177/23456789 06292430

34. Daugbjerg SB, Kahlmeier S, Racioppi F, Martin-Diener E. Promotion of physical activity in the European region: content analysis of 27 national policy documents. J Phys Act Health. 2009;6(6):805-817. doi:10.1123/JPAH.6.6.805

35. Robben AC, Sluka JA. Ethnographic Fieldwork: An Anthropological Reader. Oxford: Blackwell Publishing; 2007.

36. Meredith J. Building operations management theory through case and field Research. J Oper Manag. 1998;16(4):441-454. doi:10.1016/ S0272-6963(98)00023-0

37. Denzin NK, Lincoln YS. Handbook of Qualitative Research. 2nd ed. Thousand Oaks: Sage; 2000.

38. Corbin J, Strauss A. Basics of Qualitative Research: Techniques and Procedures for Developing Grounded Theory. 3rd ed. Thousand Oaks: Sage; 2008.

39. Weber RP. Basic Content Analysis. 2nd ed. Newbury Park/London/ New Delhi: Sage; 1990.

40. Gyapay. J, Freeman. S, Flood D. An environmental scan of caregiver support resources provided by hospice organizations. J Palliat Care. 2020;35(3):135-142. doi:10.1177/0825859719883841

41. Vanderhaeghen B, Bossuyt I, Menten J, Rober P. What is good advance care planning according to hospitalized palliative patients and their families? An Explorative Study. J Palliat Care. 2020;35 (4):236-242. doi:10.1177/0825859720938583

42. Mayring P. Qualitative Content Analysis- Theoretical Foundation, Basic Procedures and Software Solution. Klagenfurt, Austria; 2014.

43. Fisher D, Wilder-Smith A. The global community needs to swiftly ramp up the response to contain COVID-19. Lancet. 2020;10230 (395):1109-1110. doi:10.1016/S0140-6736(20)30679-6

44. Tripathi SC, Deshmukh V, Patil A, et al. COVID 19 diagnostic multiplicity and its role in community surveillance and control. Le Infezioni Medicina. 2020;28(suppl1):18-28. doi:10.14293/S2199. 1006.1.SOR-.PPA94RC.V1

45. Becker D, Sandoval E, Amin A, et al. Saliva is less sensitive than nasopharyngeal swabs for COVID-19 detection in the community setting. MedRxiv. 2020. doi:10.1101/2020.05.11.20092338
46. Kwon KT, Ko JH, Shin H, et al. Drive-through screening center for COVID-19: a safe and efficient screening system against massive community outbreak. J Korean Med Sci. 2020;35(11):123. doi:10.3346/jkms.2020.35.e123

47. Kim J, Kim DH, Sancho-Torres I, et al. An approach to outpatient screening, treatment, and community health outreach during the Coronavirus epidemic in New York city. Adv Infect Dis. 2020. 10 (3):1-5. doi:10.4236/aid.2020.103001

48. Cowling BJ, Aiello AE. Public health measures to slow community spread of coronavirus disease 2019. J Infect Dis. 2020;221 (11):1749-1751. doi:10.1093/infdis/jiaa123

49. Wan KM, Ho LK, Wong NM, et al. Fighting COVID-19 in Hong Kong: the effects of community and social mobilization. World Dev. 2020;134(10):105055. doi:10.1016/j.worlddev.2020.105055

50. Blake S, Ngo T. Rapid review of community engagement and social mobilization strategies for COVID-19 response: study description. Poverty, Gender, Youth. 2020. doi:10.31899/PGY14.1016

51. World Health Organization. Role of community engagement in situations of extensive community transmission of COVID-19; 2020.

52. Rukhsana A. Role of community participation in a pandemic situation of Covid-19. In: Public Policy and Community Development in Stressful Situations. Ankara: Development and Social Researches Publications; 2020.

53. Schiavo R. Advocacy, community engagement and cross-sectoral collaborations as key strategies during COVID-19 response and beyond: new directions for a new decade. J Commun Healthc. 2020;13(1):1-5. doi:10.1080/17538068.2020.1762983

54. Gilmore B, Ndejjo R, Tchetchia A, et al. Community engagement for COVID-19 prevention and control: a Rapid Evidence Synthesis. medRxiv. 2020. doi:10.1101/2020.06.17.20133876

55. Yu EYT, Leung WLH, Wong SYS, et al. How are family doctors serving the Hong Kong community during the COVID-19 outbreak? A survey of HKCFP members. Hong Kong Med J. 2020;26 (3):176-183. doi:10.12809/hkmj208606

56. Haines A, de Barros EF, Berlin A, et al. National UK programme of community health workers for COVID-19 response. Lancet. 2020;395(10231):1173-1175. doi:10.1016/S0140-6736(20)30735-2

57. Giri PP, Bhatia V. Time to win the war against COVID-19: how and where community medicine professionals can contribute? Indian J Community Med. 2020;6(1):9. doi:10.4103/IJCFM.IJCFM_35_20

58. Julia C, Saynac Y, Le Joubioux C, et al. Organising community primary care in the age of COVID-19: challenges in disadvantaged areas. Lancet Public Health. 2020;5(6):e313. doi:10.1016/S2468-2667(20)30115-8

59. Bakri H. Quality improvement of community health center during Covid-19 Pandemic. IJMMU. 2020;7(4):345-354. doi:10.18415/ IJMMU.V7I4.1614

60. Hoti K, Jakupi A, Hetemi D, Raka D, Hughes J, Desselle S. Provision of community pharmacy services during COVID-19 pandemic: a cross sectional study of community pharmacists' experiences with preventative measures and sources of information. Int J Clin Pharm. 2020;42(6):1197-1206. doi:10.1007/S11096-020-01078-1

61. Blake S, Ngo T. Dataset: Rapid Review of Community Engagement and Social Mobilization Strategies for COVID-19 Response. New York: Population Council; 2020.

62. Kobokovich AL, Hosangadi D, Rivers C. Supporting social distancing for COVID-19 mitigation through community-based volunteer networks. Am J Public Health. 2020;110(8):1167-1168. doi:10.2105/ AJPH.2020.305740

63. Yamani LN, Syahrul F. Public health perspective of the COVID-19 pandemic: host characteristics and prevention of COVID-19 in the community. World Acad Sci J. 2020;2(6):1. doi:10.3892/wasj.2020.62

64. Wong MC, Huang J, Teoh JY, Wong SH. Identifying a capability framework that could mitigate the Coronavirus disease 2019 Pandemic in a global health community. J Infect Dis. 2020;222 (5):880-881. doi:10.1093/infdis/jiaa357 
65. Xiang R. We will give full play to the role of social work in normalizing community epidemic prevention and control. China Society News; 2020.

66. Citizen Health Section of HIDA city. Covid-19 infection information: please use the action sheet. City HIDA. Available from: https://www.city.hida.gifu.jp/site/corona/21389.html. Accessed June 12, 2020.

67. Jack G. No smartphone? No problem. Singapore rolls out coronavirus contract-tracing device for seniors. CNN. Available from: https:// edition.cnn.com/2020/06/29/asia/tracetogether-tokens-singapore-scliintl/index.html. Accessed June 29, 2020.

68. Dallon A New survey shows US adults split on COVID-19 cell phone tracking and data collection. MSN news. Available from: https://www.msn.com/en-us/news/technology/new-survey-shows-usadults-split-on-covid-19-cell-phone-tracking-and-data-collection/arBB13NMpC. Accessed May 8, 2020.

69. Tran BX, Dang AK, Thai PK, et al. Coverage of health information by different sources in communities: implication for COVID-19 epidemic response. Int J Environ Res Public Health. 2020;17(10):3577. doi:10.3390/ijerph17103577

70. Le HT, Mai HT, Pham HQ, et al. Feasibility of Intersectoral collaboration in epidemic preparedness and response at Grassroots levels in the threat of COVID-19 pandemic in Vietnam. Front Public Health. 2020;8:648. doi:10.3389/fpubh.2020.589437
71. Tran BX, Hoang MT, Pham HQ, et al. The operational readiness capacities of the grassroots health system in responses to epidemics: implications for COVID-19 control in Vietnam. J Glob Health. 2020;10(1):011006. doi:10.7189/jogh.10.011006

72. Tran BX, Phan HT, Nguyen TPT, et al. Reaching further by village health collaborators: the informal health taskforce of Vietnam for COVID-19 responses. $J$ Glob Health. 2020;10(1):010354. doi:10.7189/jogh.10.010354

73. Chew NWS, Cheong C, Kong G, et al. An Asia-Pacific study on healthcare workers' perceptions of, and willingness to receive, the COVID-19 vaccination. Int $J$ Infect Dis. 2021;106:52-60. doi:10.1016/j.ijid.2021.03.069

74. Hao F, Wang B, Tan W, et al. Attitudes toward COVID-19 vaccination and willingness to pay: comparison of people with and without mental disorders in China. BJPsych OPEN. 2021;7(5). doi:10.1192/ bjo.2021.979

75. Nguyen LH, Hoang MT, Nguyen LD, et al. Acceptance and willingness to pay for COVID-19 vaccines among pregnant women in Vietnam. Trop Med Int Health. 2021;26(10):1303-1313. doi:10.1111/ tmi. 13666

76. Vu TS, Le MA, Huynh NTV, et al. Towards efficacy and sustainability of global, regional and national COVID-19 vaccination programs. J Glob Health. 2021;11:03099. doi:10.7189/jogh.11.03099
Risk Management and Healthcare Policy

\section{Publish your work in this journal}

Risk Management and Healthcare Policy is an international, peerreviewed, open access journal focusing on all aspects of public health, policy, and preventative measures to promote good health and improve morbidity and mortality in the population. The journal welcomes submitted papers covering original research, basic science, clinical \& epidemiological studies, reviews and evaluations,

\section{Dovepress}

guidelines, expert opinion and commentary, case reports and extended reports. The manuscript management system is completely online and includes a very quick and fair peer-review system, which is all easy to use. Visit http://www.dovepress.com/testimonials.php to read real quotes from published authors. 